Paul Hazard

\title{
Tres meses en Chile
}

Abril, 1924.

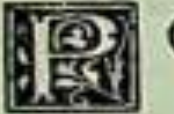

ONGO una señal en mis libros; interrumpo la lectura comenzada. Semeha hecho el honor de llamarme a la Universidad de Santiago, donde debo enseñar durante tres meses. y me preparo a partir hacia el extremo del mundo, hacia Chile.

Vuelvo a ver entonces. en el pensamiento, la vida extraordinaria de los viajeros. El puerto ruidoso. lleno de olores marinos. La oscura mole del barco. que encierra un hormiguero en trabajo. La exploración: ¿đónde están los camarotes, el comedor, el salón, el lumadero? ¿Cómo se llama el comandante? ¿Será amable el comisario? ¿Tiene el vapor buenas condiciones de navegación? La partida: el monstruo resuella, lanza gritos desesperados, respira, se mueve: los muelles se alejan. la costa se esfuma: adiós. Francia... Después, será la existencia a bordo. a lo largo de los días monótonos, las lecturas indiferentes. las siestas y el ocio: un largo intermedio de inacción. de entorpecimiento, durante el cual elevaremos a la categoría de acontecimientos considerables el paso de un navio, el ir y venir de un tropel de delfines. la aparición de una ballena o las volteretas de los peces voladores. El mar caprichoso se cansará de todos sus cambiantes vestidos, de su traje esmeralda y de su traje azul prolundo. de su traje franjeado de armiño. trasparente. glauco o gris: se incendiará bajo el sol y se encenderá de plata 
bajo la luna. Hará penetrar hasta lo más profundo de nuestro ser la modorra de sus horas sin sombra, o bien. súbitamente encolerizado. transformará esta nave. que nos parecía un mundo. en un pobre juguete pequeño y bañado por las aguas.

Veremos la comedia humana: en ninguna parte se está mejor colocado para observarla que en un sillón del puente. Alli estarán los charlatanes. que verán modo de diriggir la palabra a todos los pasajeros: los taciturnos. que de la mañana a la noche se pasean solitarios: los jugadores. que se pasan las noches en las mesas de poker: los gastrónomos, para quienes la hora divina es la del comedor. Gentes absolutamente extrañas las unas para las otras explorarán todo su parentesco, remontarán el curso de sus vidas para encontrar, por fin. un conocido común: ly qué sorpresa! Se formarán clanes y grupos intimos; se anudarán amistades y amores. Por la ociosidad. por la vanidad. por la estrechez misma de esta escena, en que los actores aprisionados se cruzan veinte veces al dia. estas pasiones se exasperarán de tal manera, que la comedia amenazará por mornentos convertirse en tragedia. Entretanto, el buen navio. despreocupado de todo, excepto de su rula, continuará trazando su camino: noche y día se percibe el temblor de sus máquinas incansables: poco le importan las agitaciones de los pequeños hombres que conduce; fiel. obstinado, se dirige hacia su puerto. Sabe muy bien que a la llegada todo se calmará: que se estrecharán la mano con una indiferencia apenas amable; que cada uno, encontrándose a sí mismo. olvidará a sus compañeros de viaje y volverá a partir hacia su propio destino.

Si, reviviremos todas estas impresiones de viaje, tan pintorescas. tan atrayentes y tan llenas de enseñanzas, que a aquel que no las haya conocido le faltará una profunda experiencia. y que una vez probadas, se imponen al recuerdo con fuerza invencible. Penetrados por los soplos de alta mar. desembarcados al fin. nos enriqueceremos al contacto de nuestros hermanos lejanos y. en cambio. les ofreceremos lo mejor de nosotros mismos.

Se reprochaba antes a los profesores el que no salieran de 
sus bibliotecas y sólo hicieran por viaje el trayecto que lleva de su gabinete de trabajo a su cátedra. Hoy van de muy buen grado por todo el vasto mundo: tanto mejor si su saber llega a ser menos libresco y más ampliamente humano.

Los Andes, 19 de Mayo.

Sentimos un pequeño desdén hacia los pasajeros que terminan su viaje en Buenos Aires: itan prontol Dor nuestra parte. iremos tan lejos como es posible ir. y no abandonaremos el buque sino para tomar el ferrocarril. Durante veinticuatro horas, hasta Mendoza, el tren corre a través de la pampa argentina. $\mathrm{Ni}$ una ondulación viene a inteŕrumpir la monotonia de la interminable planicie; ni casas, ni árboles: ¿qué se han hecho nuestros vallados? ¿dónde están nuestros campos tolalmente humanizados? Avestruces, ovejas, bueyes, animan hasta la lejania la hierba seca: ¿dónde están nuestros pastores y nuestros boyeros, y nuestros serviciales perros. que no permiten que nuestros rebaños se conviertan en hordas? Ellos saben que la tierra de Francia no es grande: he ahí por qué los tienen bien guardados. Muy pronto el mirar por la ventanilla nos da una sensación penosa: tal es la obstinación de la llanura en conservarse siempre igual. en rehusar la más pequeña variación. Un polvillo implacable invade el vagón a despecho de la doble ventana; cubre los cabellos, se adhiere a los rostros, penetra en la garganta; lo respiramos, lo bebemos.

En Mendoza, no se desciende sino para sacudirse antes de comenzar un nuevo viaje, esta vez en la altura. Este pequeño tren que espera es el trasandino, que tiene la pretensión de escalar la Cordillera. Parte, sube: se detiene en las estaciones hechas a su semejanza, tan pequeñitas. que parecen juguetes de niños; todos los viajeros descienden para recrearse. Escalando las pendientes. deslizándose al borde de los montes, atravesando los valles, rozando el borde de los precipicios, rodeando las cumbres, se lanza 
hacia adelante con un esfuerzo enorme. Indudablemente terminará por llegar allá arriba, a tres mil doscientos metros. último extremo de su ambición. Entre tanto, el paisaje. que ninguna vegetación adorna. toma poco a poco un carácter áspero. En las líneas, es una sucesión de perfiles audaces, y en los colores, es un enrojecimiento continuo de las tierras aglomeradas y de las rocas áridas. La nieve aun no ha invadido la montaña: apenas se advierten algunas blancuras eternas. A intervalos. encontramos grupos de hombres ocupados en asegurar un terraplén. en cavar un túnel, en edificar las galerías de madera que protejerán contra los rodados de nieve esta línea paradojal: extraños habitantes de las alturas, cubiertos de pieles de animales, con abrigos de lana, enanos de las montañas gigantes.

Por fin la ascensión ha terminado: se detiene por costumbre alli donde se detenían las antiguas caravanas, sobre una estrecha meseta que las cumbres circundan como las puntas de una corona. Apenas tenemos tiempo para contemplar los reflejos del sol sobre las neveras: ahora es preciso deslizarse hasta el llano. sobre las abruptas vertientes de las laderas chilenas.

Poco a poco cac la oscuridad: la fantasmagoria de afuera se desvanece y se apaga. Sólo el ruido de los frenos indica un descenso vertiginoso. Sentimos pesar hondamente el cansancio de la fatiga acumulada: parece que estuviéramos condenados a rodar elernamente en la oscuridad.

Finalmente, los Andes, al pie de la Cordillera. Desciendo en una estación desconocida. obligado a correr detrás de los mozós que se han hecho cargo de nuestras valijas y que marchan a paso ligero, en la necesidad de buscar las maletas para la visita de la aduana: cansado, agotado. entorpecido por el sueño. arrastrado por la ola de los que llegan, repentinamente creo oir una voz que grita mi nombre. No hay error posible: es a mi a quien llaman: ¿qué milagro es éste?

Quien me ha llamado es un profesor de la Universidad de Santiago. delegado expresamente hasta la estación fronteriza para dar la bienvenida a su colega extranjero, para evitarle toda molestia. para viajar con él y guiarlo. por fin. a su llegada a la 
ciudad que deberá ser su nueva residencia. Como le hubiera sido imposible reparar en mi en medio de la multitud, ha usado de un medio heroico: se ha puesto a gritar mi nombre: así es como el encuentro pudo producirse. Volviendo a partir bajo su guia, pienso que desde entonces toco al término de mi ruta. que mi tarea va a comenzar; y bendigo al mismo tiempo la exquisita cortesia de un país que ha querido darme desde los comienzos esta prueba de hospitalidad: feliz presagio que sólo los dioses favorables pueden enviar.

Santiago de Chile. 21 de Mayo.

He estado a punto de equivocarme como aquel viajero legendario que al atravesar una campiña donde las labradoras se hallaban ocupadas en escardar los plantios, anota en sus apuntes que en esa región todas las mujeres caminan en cuatro pies.

Electivamente, en mis comienzos acabo de recibir una impresión atrayente. Hoy es día de fiesta patriótica; las calles aparecen empavesadas: las tropas desfilan. Ahora bien. es muy poco decir que el uniforme de estas tropas ha sido imitado del alemán: reconozco el uniforme alemán mismo. Nada falta en él: ni las botas, ni las mochilas de piel leonada, ni el casco en punta.

¿Es preciso deducir de esto que todo Chile no es sino una Germania? Cuidémonos. por el contrario, de tal tentación: pues es gran pecado generalizar muy de prisa. No pensemos nada por el momento, o pensemos que hay en esto un pequeño misterio que el porvenir nos explicará.

Observemos mejor a la muchedumbre que se precipita al paso de los soldados: orgullosa, emocionada. Se me dice que el patriotismo es aquí uno de los más profundos sentimientos: que no hay sacrificio en que la nación no consienta para conservar este ejército fuerte y disciplinado. Veo la prueba de cllo: numerosos campesinos a caballo siguen a las tropas: han venido de los pueblos próximos o lejanos para demostrar su ad- 
hesión a la patria y su fidelidad al ejército. Tienen semblante de orgullo. firmemente montados sobre sus cabalgaduras. hieráticamente frajeados con sus grandes ponchos.

\section{EN LA UNIVERSIDAD}

Qué día tan luminoso! Parece que la estación cruda ha comenzado: los europeos recién llegados no se habitúan fácilmente a la idea de que sus meses de calor son aqui los meses de invierno y a que la Pascua sea una fiesta de verano. Acaso las lluvias lleguen más tarde: lo cierto es que esle día de Otoño es suave como nuestras primaveras. En Santiago de Chile. los latinos encuentran de nuevo. lejos de las violencias de los trópicos. amigable y bienhechor, el sol, su grande amigo.

La ciudad está trazada en cuadros. a la manera de las ciudades americanas. Es ésla. por lo demás. la única semejanza suya con sus grandes hermanas del Norte. No invade el cielo: ño se hunde en la tierra: no se estiende fuera de toda medida. Tiene sus calles sociales, un centro, un corazón. Es española. por su noble catedral, por el palacio del Gobierno, la Moneda. del más elevado estilo. y por sus casas con patio. O. más bien. era española. pues la vida moderna es despiadada con los vestigios del pasado: era española, y de ello conserva aún algunos recuerdos en ciertos lugares.

Nada más agradable que este primer contacto con una ciudad extranjera: es un rostro que desciframos. En Santiago de Chile. un rrancés se siente menos desterrado que en Londres. por ejemplo. La distancia nada influye en esto: basta que la raza, muy próxima. nos dé la impresión de una intimidad que es fácil descubrir. Por lo demás. los rezagados que alimentan respecto de la América del Sur ideas a menudo absurdas y a veces hirientes. comprenderian pronto su error si alcanzaran hasta aqui. Una hora de paseo bastaria para mostrarles la sobria elegancia de las mujeres y la seguridad de su gusto. Nada chillón, nada pesado: por todas partes. al contrario, el sentido de las discretas armonias. Ahora. si es verdad que nuestro 
pueblo es particularmente sensible a estas mismas cualidades de refinamiento $y$ de medida, me complace de verdad descubrir. a la primera mirada, este evidente parentesco.

Los edificios de la Universidad se hallan en la Alameda. en la Avenida de las Delicias, como se la llama. Y es deliciosa, en efecto. esta inmensa avenida ornada de árboles seculares. bordeada de residencias elegantes, paseo, parque y boulevard. - ¿Podemos ver al Rector?-Atraviese Ud. el patio y pregunte al secretario: el Rector le espera ya.

He atravesado el patio y entrado a la sala donde los retratos de los rectores fallecidos os observan con esa mirada celosa que tienen los muertos para los vivos. y héme aqui frente a don Gregorio Amunátegui Solar. Es él de aquellos a quienes creemos reconocer cuando los vemos por primera vez: lanta naturalidad hay en su acogida y tanta afabilidad en su siBuenos dias, mi querido colega!. . tanto atractivo en toda su persona.

Don Gregorio es hombre de raza. Cuando sale de la Universidad, para subir a su coche, puede ver la estatua de su padre y de su tio. hombres de ciencia y hombres de Estado. que se eleva en la Alameda. Don Gregorio tiene el trato refinado que da el mundo. a pesar de que niega ser mundano. Don Gregorio conoce bien Europa: sus primeros estudios le llevaron a Alemania: su natural inclinación y sus afinidades profundas le llevan hacia Francia. Está dotado de la más fina y más flexible inteligencia, no sin algo de humor: a menudo su mirada sonrie tras de sus lentes. A pesar de todos los cargos que ha ocupado. a pesar del enorme peso que soporta todavía,-el de administrar a la vez la enseñanza superior y la enseñanza secundaria de Chile,--don Gregorio está lleno de fuerzas: si conserva su barba blanca. es sólo por coquetería. Como médico, conoce la patología de las almas: como cirujano de mérito. sabe que es preciso no retroceder ante una operación. de tiempo en tiempo. Ama a su pais. no con ese amor inerte y contemplativo que consiste en alabar todas las cosas. sino con un amor activo que mira hacia el porvenir. 
Don Gregorio allana mis dificultades, no sólo porque se desembaraza pronto de la pequeña organización que supone mi llegada.-comienzo de los cursos. dias. horas. locales; presentación a los altos funcionarios de la Universidad, a los decanos. a los colegas: presentación a las autoridades chilenas:- sino porque él mismo se anticipa a mis dudas. y me orienta en esta atmósfera desconocida. ¿Esté Ud. seguro de una cosa, me dice: es, en el orden intelectual y moral. la proximidad de Chile a la tradición francesa. Nuestro pensamiento está muy cerca del vuestro, porque no ha dejado de nutrirse de él desde el día de nuestra emancipación. Y me refiere cómo los libros que despertaron su curiosidad de joven. son libros franceses: cómo la cubierta color salmón de la Revue des Deux Mondes. a la que su padre estuvo suscrito desde su fundación. le ha sido familiar desde su adolescencia. Nada desea más vivamente que ver reforzarse los lazos espirituales que unen nuestros pueblos.

Veré a menudo la vasta y clara sala donde fuí acogido por primera vez. la mesa cargada de libros. y rey de este reino, a don Gregorio Amunátegui Solar. La Universidad no será un lugar de tránsito donde no deba aparecer sino en las horas de mis cursos. sino una de mis residencias: seremos vecinos. Le interrogaré algunas veces, y él me interrogará a menudo. preocupado en conocer mejor la enseñanza francesa para adoptar. si es posible. lo que pueda ser útil a la enseñanza chilena. ¿Cómo son designados. en forma precisa, vuestros profesores? ¿En qué consiste exaclamente vuestra agregación? ¿Cuántas horas semanales os exigen en vuestros cursos? ¿Cómo proceden Uds. a la corrección de los trabajos? Y. sobre todo. ¿qué lugar reservan Uds. a los estudios puramente desinteresados, a aquellos que no responden a ninguna utilidad inmediata y contribuyen, por su naturaleza y por sus métodos. a elevar el nivel intelectual de una nación? Se advierte en él un espiritu en perpetua labor, que no se paga de palabras; sabe que no basta enunciar un posible progreso para transformarlo en adquisición: pertenece a la especie de los realizadores, que jamás conciben una idea sin buscar al mismo tiempo los medios de 
acción que corresponden a ella. Se comprende asi el ideal, a la vez nacional y humano. que anima a este hombre, a quien no se podría conocer sin estimarle.

\section{LOS CURSOS}

Heme aqui en el ejercicio de mis funciones. sentado ante una pequeña mesa que se avanza como una punta de tierra en medio del auditorio, ante el vaso de agua ritual. frente a la instalación de telefonia sin hilos que transmitirá mis palabras a los amigos lejanos e invisibles: signo de los tiempos nuevos. Aqui comienza otro orden de dificultades, más personal. iFeliz el que se sienta con desenvoltura. con facilidad, mueve la botella sin el temor de vaciar su contenido sobre las notas, y aun se complace con sus propias palabras! Por mi parte, jamás he comenzado una lección sin experimentar un deseo vehemente de hallarme a cien leguas de distancia: los cinco primeros minutos me resultan terribles.

Pero es tal la benevolencia del público que me escucha. que muy pronto siento cómo se establece el contacto. No se me rehusará, estoy seguro, esa simpatía sin la cual el que habla queda reducido a predicar en el desierto: por el contrario. se me prestará la más viva atención. Hay a veces un curioso fenómeno en virtud del cual los que tienen la costumbre de hablar en público se desdoblan. Dos personajes coexisten en ellos que, repentinamente. se separan. El primero continúa emitiendo sonidos, construyendo frases, desarrollando mecánicamente su tarea de orador. El segundo, se desprende. se escapa, vaga. observa, fija su atención sobre un detalle menudo, coge de pasada los signos infalibles que permiten advertir la atención o la desatención del auditorio. Oye los bostezos ahogados, las retiradas estratégicas. los cuchicheos de sillón a sillón. las conversaciones furtivas; 0 , a la inversa, ve que nadie se mueve. que la atmósfera se entibia. que los accesos de tos terminan. que los resfríos se curan como por encanto. Inmediantamente da cuenta a su doble del resultado de estas observaciones per- 
sonales con sus comentarios.-Aquí, mi doble no me ha referido nada inquietante.

Los cursos tienen lugar tres veces por semana; dos veces en el salón de honor de la Universidad. cuya disposición se asemeja mucho a la de un teatro. Tengo el placer de encontrar varios centenares de personas capaces de coger lodos los matices de nuestra lengua; tan al dia en nuestra literatura. que podemos hablar con sobreentendidos; bastante fieles para seguir en todo su desarrollo el desenvolvimiento de un curso que evoca sucesivamente la Revolución Francesa y la Emigración. Chateaubriand y Mme. Staël. Napoleón y los ideólogos. la discusión entre clásicos y románticos. la batalla de Hernani y la evolución de nuestra literatura hasta 1848. Terminada la lección, vienen espontáneamente a buscar al profesor: discutimos: me piden dalos precisos acerca de ciertos puntos: se hacen valer objeciones. críticas; otro signo igualmente infalible de que la enseñanza ha sido provechosa. Espontáneamente se señalan preferencias. instructivas para mi. Chaleabriand no llega a vencer cierta hostilidad. porque no se separa al hombre del autor. y se encuentra al hombre desagradable. Hugo, que ha ejercido sobre la literatura chilena una profunda influencia. es considerado aún como uno de los más grandes poetas de que pueda honrarse la humanidad. Vigny, menos conocido, sorprende y conmueve: un oyente me entrega una traducción de Eloa. que èl acaba de publicar. Musset continúa siendo uno de los preferidos. Aqui. como en lodas partes. la gran figura de Lamartine gana en altura, a pesar del tiempo transcurrido.

El tercer curso no se realiza en la Universidad misma. sino en el Instituto Pedagógico. donde se preparan los futuros profesores de la enseñanza secundaria. y que corresponde a la vez a nuestra Escuela Normal Superior y a nuestra Escuela de Sèvres. El lugar de la escena es menos solemne: paredes blancas y desnudas, bancas y pupitres, pizarrón: todo igual a nuestra casa de la calle de Ulm. la cátedra del prolesor es una silla de paja. El carácler de la enseñanza es más técnico: se trata de indicar a los alumnos nuestros métodos de historia literaria: 
cómo tenemos por costumbre formar una bibliografia. componer una disertación o una lección: sobre todo explicar los textos de nuestros autores modernos. Estudiar una página de algún escritor, sorprendiendo su carácter especifico. no sólo con justeza y exactitud. sino sin olvidar nada de los derechos de la sensibilidad: separar lo esencial. discerniendo los matices: luchar contra el poder de la pereza y de la ilusión. evitando las generalidades ociosas y aproximándonos siempre al texto con espíritu flexible y exacto: luchar contra la tentación de charlatanería. aun de la erudita. recordando que el buen gusto está formado de sabiduria y de medida; he aqui el estudio en que nos ocupamos $y$ en que se ocupan mis alumnos. ¿Quién hablaba de dificultades? ¿Qué se hicieron mis primeros temores? Ayudado por mis excelentes colegas chilenos, a quienes no debo sino felicitaciones. en esta austera sala de clases. símbolo de nuestro austero trabajo, ante estos jóvenes rostros atentos, olvido la distancia y el destierro: he vuelto a encontrar mi medio, mi razón de ser y mi verdadera vida. Perlenezco a una gran familia. que se extiende más allá de los muros de mi ciudad. más allá de las fronteras de mi país; pertenezco al vasto colegio de los que estudian para enseñar. Soy hermano de estos estudiantes que me escuchan; y ellos son mis hermanos menores. Acerquémonos a ellos con todas nuestras fuerzas: tratemos de comunicarles los frutos de nuestra experiencia: cojámoslos de la mano dulcemente para ayudarlos a encontrarse a sí mismos y mostrémosles su camino. ¡Entreguémonos: la tarea vale la pena de hacerlol Esforcémonos en ser dignos del gran honor que se nos hace confiándosenos a aquéllos que mañana tendrán bajo su guarda el espiritu y el alma de las generaciones que se levantan. Feliz si la juventud suya me instruye a su vez: si me enseñan a encontrar de nuevo la emoción de una sensibilidad vivisima: si su alegria bulliciosa me lleva al recuerdo de mi juventud y si mi espiritu se refresca con el suyo. Feliz. sobre todo. si ellos quieren brindarme, en cambio. algo de la amistad que con intimo agrado les ofrezco. Asi lo espero: asi lo creo. Timidos al principio. helos aqui que se acercan y que vienen ha- 
cia mi. Continuemos la lección por largas conversaciones; demos ánimo a los fieles discipulos que de calle en calle y de pregunta en pregunta, atraviesan conmigo toda la ciudad y que no me abandonan. en mi residencia, sino muy a pesar suyo.

\section{UNA CRUZ DE PLATA}

Entre las virtudes chilenas, que son numerosas. señalemos decididamente la hospitalidad. Hay paises en que quedamos reducidos a mirar con envidia las ventanas iluminadas, detrás de las cuales los demás se reúnen. y a limitar nuestras relaciones sociales a los cocheros y a los mozos de holel. Nada de esto: aqui la hospitalidad no es sólo. fineza o rito: es generosidad de corazón. Seria muy ingrato el extranjero que no conservara el recuerdo de tantas casas amigas. donde fuera repetida y delicadamente atendido.

Fué acogido por la Colonia francesa, que le proporcionó el gran placer de sentirse en familia. tan lejos de Francia y tan cerca de ella: presente por su espiritu y por su alma: presente en los solos nombres de los convidados, en el sabor del terrunoo $y$ en las claras palabras: presente por sus viejas. amables canciones y dulces aires antiguos. Fué acogido por los vascos. que conservan frente a la Cordillera el recuerdo de sus Pirineos, de sus juegos, de sus danzas, de sus coros antiquísimos. $\mathrm{Y}$ por tantos franceses, en su hogar. Y por tantos chilenos. amigos de Francia: por el Presidente de la República, por el Presidente del Senado. por el Presidente del Consejo. por el Intendente de la Provincia: y por tantos y tantos otros. cuya lista seria muy larga. pero que él conoce bien.

Ciertamente. en medio de estos almuerzos, de estos tees, de estas comidas como no las hay sino en Jauja. es preciso recurrir a todo nuestro ascetismo para no convertirse en un glotón: iay de esos pobres estómagos que estân a régimen. legumbres y compolas, y ay de los bebedores de agual Bajo el claro cielo de Chile madura un racimo escogido. que los sabios cuidados de nuestros languedocinos o de nuestros borgoñones. especial- 
mente traidos. transforman en un vino delicioso. Pero, donde se hace necesaria una suerte de virtud heroica es en acostumbrarse a no considerar los obsequios, las atenciones, los halagos. como las cosas más naturales del mundo. Porque no sólo se os invita a participar de los bienes perecederos: se desea que llevéis también algunos presentes durables, como esta cruz de plata. cuya muy novelesca y muy verídica historia merece. sin duda, ser referida.

$\mathrm{Ha}$ sido tallada toscamente y golpeada a martillo; apenas una linea vacilante y sinuosa señala en ella una voluta que parece un adorno. Otras cruces pequeñitas. lisas, desnudas, vienen suspendidas por anillos a sus cuatro brazos iguales. Joya primitiva, adorno antiguo de las mujeres araucanas, en el Sur.

Habia una vez en Lautaro, hacia el Sur, un cacique rico y muy considerado. que en vez de amar a la más anciana de sus mujeres, y por consiguiente a la más probada. prefería a la más bella, a la más joven. a la más vivaz. La más inquietadora fambién. pues él tomaba su jovialidad por ligereza, su gracia liviana por coquetería. y no estaba seguro de que ella le amara, correspondiéndole. Ella le amaba, por el contrario: le amaba fiel. mente. Pero como él se guardaba, según la costumbre de su raza. de fiar a las palabras. que son vanas. sus profundos sentimientos: como disimulaba cuidadosamente sus sospechas y sus temores, la joven esposa, viva, alegre, pueril, continuaba exitando sin saberlo los celos apasionados de su marido.

Una noche le traen ensangrentado a su choza. Nada dice. Pero ella sabe por otros que ha provocado a un cacique de la vecindad, porque veía en éi un rival feliz. Ellos se han batido briosamente.

Llama ella al médico, y le ayuda a curar las heridas, silenciosa. ¿Cómo disculparse? ¿Y para qué? Duesto que el señor se calla. ella calla también, ella callará. Llega el machi de la ciudad, curandero y mago. que trae un mensaje de paz. . Cuido. dice, a un hombre a quien tú has provocado y que está próximo a morir. Me ha encargado decirte que te engañas: que jamás ha tenido ninguna relación con la mujer de quien sospe- 
chas; jura que ella y él son inocentes.. El machi transmite este juramento y lo acompaña de temibles invocaciones.

El cacique esía conmovido: un combate se libra en su alma. ¿Si este hombre dijera la verdad? ¿Si él se hubiese equivocado? ¿Si fueran sus celos ciegos y sin razón? Pero se trata. ta! vez. de una argucia. Todos saben que una herida se envenena y llega a ser mortal cuando aquél que la ha causado continúa odiando a su victima. El machi quiere salvar a su cliente. ponerlo al abrigo de un rencor que lo mataria. Miente.

En la choza siempre en silencio, las horas suceden a las horas. los días a los días. El cacique se restablece poco a poco: llega el momento en que no tiene necesidad de los servicios del médico. le ofrece los presentes habituales y le dice adiós. Entonces la joven se levanta. arranca la cruz de plata que lleva sobre el pecho y se la ofrece al médico. diciéndole: «Nada tengo: no poseo sino esta cruz. Te la doy, recibela, puesto que has salvado al hombre a quien amo.

\section{CONVERSANDO}

¿Observa usted la Cordillera?. me dice un amigo chileno que me encuertra en contemplación ante el macizo que domina la ciudad y que el poniente tiñe en este momento. no sólo de púrpura y oro. sino de violeta, de azul. Usted la admira. y tiene razón. Pero jamás la amará usted tanto como nosotros: es nuestra bienhechora. De sus nieves, de sus ventisqueros. vienen las aguas que dan al sur del pais su fecundidad: los años en que ella no quiere molestarse. nuestras hierbas se secan y nuestros rebaños mueren. Guardiana bondadosa, impide que los animales dañinos pasen: no hay en Chile fieras ni serpientes: es a la Cordillera a quien, con razón o sin ella, agradecemos este privilegio. Nos place escalar sus flancos, cazar los guanacos que viven en sus rocas: ella nos da nuestro aspecto pintoresco; nos proporciona algo de lo sublime. Pero. al mismo fiempo. es celosa: nos encierra. No solamente vivimos en 
el rincón del mundo: si nos descuidáramos. quedaríamos prisioneros.

.He aquí por qué nuestro gran deseo es evadirnos. mantener contacto con la vieja Europa, nuestra antepasada; ir a Madrid, a Roma, a Londres, a Berlin: a Paris, sobre todo, que nosotros preferimos a todas las ciudades del mundo. He aqui por qué, también, nos ocupamas en hacer venir de Europa mensajeros, como usled...

$\mathrm{Mi}$ amigo es uno de esos chilenos que han rendido su bachillerato en la Sorbona. Se ha apropiado tan bien nuestras maneras de lenguaje y aủn nuestro argot. que a veces me extraña oirle hablar castellano: no me parece natural. Pertenece a la clase escogida de la nación: tiene excelente trato mundano y espíritu claro y agudo. Y ya que tiene confianza suficiente conmigo para decirme toda la verdad, aun en lo desagradable, y pues le veo en disposición de conversar. le interrogo: ¿Cuál es con justeza la posición intelectual de Francia en Chile? No se resiste para contestarme.

Usted sabe, me dice,-o, mejor, usted no lo sabe, pues los franceses ignoran muy a menudo to que lienen mayor interés en conocer, - que ustedes ocupan aqui lugar de privilegio. Nuestra Independencia es hija de vuestra Revolución; observe nuestra bandera: sus colores son los vuestros, Los historiadores de nuestra literatura le dirćn que nos hemos inspirado, en el curso del siglo XIX, en vuestras diversas corrientes de pensamiento: tuvimos la ideologia y el positivismo: hemos sido románticos después de vosotros; sufrimos el contragolpe de vuestro naturalismo. Os seguimos.

- Después hubo una especie de detención. Fué esto,-en la medida en que es posible señalar fecha a tales fluctuaciones. - algunos años después de vuestra guerra con Alemania. No quiero decir que no hayamos sido impresionados por el prestigio de la victoria: es humano, ¿no es verdad? Pero querrá concederme que ustedes tampoco quisieron provocar nuestro entusiasmo: pareciais haber perdido confianza en vosotros mismos: ya no estábais aquí. Desapareciais: y. entre tanto. Ale- 
mania venia a nosotros, poderosa, insinuante, sin pedir nada. sino el ofrecerse. He aquí como fomó la dirección de nuestro ejército, hasta modelarlo a imagen del suyo. He aquí como. al fundar nuestro Instituto Pedagógico. llamamos maestros alemanes, los cuales eran. por otra parle. de un valor incontestable. Si hablara del comercio. tendría muchas otras cosas que decirle: pero no es éste su oficio. y en esto nada entiende usted...

Concedo no entender nada de comercio, y le ruego continuar instruyéndome.

- Lo que deseamos. continúa él. es fortificar nuestro espiritu nacional por los mejores aportes extranjeros. Por lo tanto. estamos abiertos a todas las influencias europeas y aún a la influencia de la América del Norte, y con mayor razón: algunos de nuestros maestros. que han viajado, han sido impresionados por la prosperidad material de las escuelas en los Estados Unidos, y por los resultados práclicos que ellas obtienen: no les desagradaria imitar su organización. Tenemos entre nosotros instituciones alemanas que nos proponen su método estricto y su fuerte disciplina. Tenemos escuelas inglesas: el inglés progresa continuamente como lengua social, desde hace algún tiempo. El italiano no tenía aún el lugar que se le debe: acabamos de crear una cátedra de italiano en el Instituto Pedagógico, y yo estoy de esto muy contento. Gracias a todos estos datos, merced a todas estas experiencias. podemos a la vez perfeccionarnos en nuestro propio ser y participar en forma creciente de los progresos. de las agitaciones de la colectividad humana.

¿Quiere decir esto que. después de haber ocupado una posición privilegiada. vosotros. los franceses. corréis el riesgo de ser ahogados por la concurrencía mundial? Podéis estar seguros... Si hay un pueblo al cual nos lleven con preferencia nuestras afinidades intelectuales. ése es ahora y será siempre Francia. Vuestro pensamiento es lo bastante parecido al nuestro para no asustarnos y lo bastante diferente para instruirnos. Siempre son vuestros libros los que nuestros jóvenes leen con mayor agrado: 
se consumen en Chile incomparablemente más obras francesas. originales o traducidas, que obras españolas. Siempre es vuestro arte el que nos seduce: siempre vuestra lengua la que nos sirve de intérprete universal.

Puesto que comenzáis a ayudaros vosotros mismos. el cielo os ayudará. Os hemos visto volver. al principio como tímidos exploradores y por tanteos: enseguida. con más decisión. Ya no contaréis más con el número, lo temo muy deveras: pero nada habéis perdido en la calidad: el Instituto Pasteur. la Escuela de Derecho, la Facultad y la Escucla de Medicina, la Sorbona, son nuestros inspiradores. Parece que se ha dado un paso decisivo el dia en que, gracias al rector Amunátegui y al profesor Georges Dumas, habéis llegado al acuerdo que nos valdrá todos los años un curso de civilización francesa: filosofia, el año último, con M. Abel Rey: literatura, este año, con usted...

Aqui mi interlocutor se detiene, reflexiona y me interroga:

- ILa civilización francesa!... dice. Curioso país el vuestro: extraña nación esta Francia: la amo: creo conocerla, y siempre estoy lejos de comprenderla. Lo que hallo de más extraordinario es que vosotros representáis al mismo tiempo dos tendencias: ya se trate de una o de la otra, se invoca a Francia como testigo histórico y aun como símbolo. Ahora bien. estas dos lendencias son contradictorias. Algunos de entre nosotros os aman porque sois, a sus ojos. el ejemplo viviente del poder de la tradición, del poder de la fe; y otros os aman porque sois la Revolución siempre alerta. ¿Cómo coordina usted esto?

Tal vez puede ser, digo, que la civilización francesa no es un dogma definitivamente detenido. Es una investigación: es una ansiedad; es un deseo siempre inquielo de lo más verdadero y de lo mejor. Con todos nuestros defectos, que son numerosos. por lo menos tenemos la virtud de llegar hasta el término de nuestras ideas y de ponerlas por obra. He aqui por qué podemos representar a las miradas de los extranjeros, principios opuestos: estos principios los ensayamos nosotros... 


\section{EL 14 DE JULIO EN SANTIAGO}

-Usted verá cómo se celebra el 14 de Julio: usted lo verá. Las fiestas duran tres dias: y iqué fiestas!...

Lo que no se me habia predicho es la emocion que yo sentiría. ¡Cuánta emoción! y. ¿por qué? Por razones dificiles de explicar, porque pierden, cuando queremos analizarlas. lo que tenian de más intimo. Por esas flores que encuentro en mi casa, enviadas por amigos chilenos, anudadas con el lazo tricolor. Por las cartas dejadas en mi puerta, y por los sentimientos de que ellas son intérpretes: -Reciba usted nuestros saludos en este gran dia de gloria.... Le saludo con afecto muy parficular en este dia francés y universal.... Por la sorpresa que tuve al abrir los diarios, en la mañana: no sólo el diario francés. que se llama La Dafrie, sino El Mercurio. La Nación. El Diario Ilustrado, celebraban el 14 de Julio, en arliculos de fondo, en crónicas, en anécdotas, en fotografías, en composiciones alegóricas y aun en un artículo en francés que leo en la primera página de El Mercurio. Por esta ceremonia organizada por los antiguos combatientes, tan simple y tan trágica, en el cementerio. Dor esta misa en que todos se hallaban reunidos, cualquiera que fuera su fe: cuando los cobres estallaron bajo las bóvedas y los ecos de ia Marsellesa vinieron a quebrarse en las columnas, ¿quién no se habria sentido temblar? La iglesia aparecía pequeñisima para la multitud reunida en ella: sentianse flotar sobre esta multitud. mezclados indisolublemente, el duelo y la gloria. la esperanza y la ansicdad. la confianza en los destinos de Francia y una gran piedad por los muertos.

Para todos hubo alli su parte: para los pequeños, para los medianos y para los grandes. Un baile infantil, con juguetes entregados en sorteo, tan hermosos, que los niños se olvidaban de bailar para observarlos. Una fiesta deportiva. una lujosa presentación de bicicletas manejadas por vigorosos muchachos en busca del honor de la victoria. Una recepción en la Legación de Francia. Un te para ayudar a las obras de beneficencia; el em- 
bajador de los Estados Unidos hubo de pagar. no sólo de su presupuesto, sino como gasto personal, con toda su embajada: y los antiguos combatientes de la colonia inglesa no olvidaron enviar un gran cesto de flores. Un baile. Una representación cinematográfica, que terminó por satisfacer a los más infatigables. después de estas festividades. de las cuales la más brillante fué sin duda el banquete.

Se verificó bajo la égida del conde Joseph de La Taille, presidente de la Colonia Francesa: ¿quién hizo oir jamás bajo el cielo chileno un acento más deliciosamente turenés? ¿quién ganó más fácilmente los corazones por el invencible destello de simpalia que despide? ¿quién se multiplicó tanto y tanto se consagró en donde se tratara de hacer amar y estimar a Francia? Cuatrocientos cubiertos o más. La sala de un cinema. acondicionada expresamente para la circunstancia. se halla toda adornada de banderas chilenas, de banderas francesas; tanto mejor muestran asi su semejanza fraternal. Dos bandas militares estremecen el aire sucesivamente. Los comisarios se agitan porque llegan las autoridades. los representantes del Gobierno, los representantes del Cuerpo Diplomático. con el Nuncio al frente: es una tradición, para nosotros singularmente enorgullecedora, que los más altos dignatarios del país y los ministros de las naciones amigas. sean este dia los huéspedes de la colonia francesa. Llega una banda: es la de los hermanos de San Vicente de Paul. la que en los momentos más críticos de la guerra. recorría las calles de la ciudad tocando la marcha Sambre-et-Meuse con tanta energía, que los corazones abatidos se sentian renacer. Prueba no haber perdido nada de su vigor después de la paz. haciendo resonar virilmente la Marsellesa. Apenas ha terminado ésta, otra Marsellesa comienza, cantada esta vez por un coro de niñitas. doblemente preocupadas de elevar la voz y de pronunciar el francés a la francesa. Obtienen éxito maravillosamente; y una de ellas, que se separa para recitar un homenaje, recibe de manos del Encargado de Negocios de Francia un reloj-pulsera de que ella no está poco orgullosa: asi como la reina de las reinas, en Deris. 
Los tapones saltan: es la hora del champaña y de los discursos. Algunos de los convidados toman un aire de resignación: la mayor parle se aprestan para oir como conocedores las frases del lenguaje oficial. Pero ¿qué digo? No es elocuencia oficial lo que escuchamos: son sencillos y hermosos discursos que adquieren en este día y en este lugar. un excepcional carácter de dignidad y de nobleza. Cuando uno de los oradores recuerda el 14 de Julio de 1914. Ileno ya de angustia por la amenaza cada dia más cercana: la movilización: la partida de los franceses residentes en Chile, que no han trepidado en venir. desde el extremo del mundo, para defender a la madre patria: entonces se comprende lo que tal palabra. vuelta repentinamente a su fuerza primera y a su sentido profundo. significa de deber, de sacrificio y de amor: $y$ el recuerdo de un pasado tan próximo. tan grande, tan doloroso, reviviendo tolalmente, nos hace sentirnos de nuevo conmovidos y temblores.

Sigo sobre los rostros las contracciones que hacen los hombres para impedir que sus ojos sellenen de lágrimas. cuya aparición sería, como es sabido. contraria a su dignidad. Vanos esfuerzos: las lágrimas indiscretas encuentran siempre su camino. Después. me doy cuenta de que yo mismo no veo tampoco muy claro, y me estuerzo en librar a mis ojos de este velo húmedo que los cubre.

\section{EN LAS ESCUELAS}

Gracias a la amabilidad extrema de los directores y directoras. que no sólo han permitido $\mathrm{mi}$ visita, sino que la han solicitado, no he limitado mi tarea a hacer mis cursos: a Dios gracias: también he visto mucho, he oido mucho: he recorrido numerosas escuelas como invitado y como amigo.

Una de las primeras cuyo umbral he franqueado es el Instituto Nacional, liceo modelo, al cual muchos chilenos que han llegado a ser ilustres en su patria, deben su formación. Un orden perfecto reina aquí; ninguna inscripción sobre las murallas. ningún grafitto, ninguno de esos juicios, enojosos que los maes- 
tros poco populares deben tomar como una lección de humildad o como un saludable consejo. Ahora bien. se llega a estos resultados maravillosos sin ninguna medida de rigor: se desconocen los castigos, y la disciplina que admiro aqui es totalmente moral, Junto al Instituto Pedagógico. funciona el Liceo de Aplicación. cuyo análogo no existe en Francia, a lo menos para la enseñanza secundaria; es otro liceo modelo en donde los normalistas vienen a hacer su aprendizaje como maestros. Lo he visitado varias veces: he visitado liceos de niñas, escuelas normales de preceptores y preceptoras, el Instituto de Educación Fisica, la Escuela de Bellas Artes, la Escuela Naval: por lo menos algunas de las escuelas francesas que han fundado y sostienen diversas congregaciones. Algunas veces, era para asistir a una fiesta: otras. para oir una conferencia: a veces. para participar en una sesión de trabajo. Nada. como es muy justo. atrajo más mi atención como las clases de francés.

El hecho es que, habiendo constatado en varias ocasiones el excelente conocimiento que tienen del francés los chilenos, me venia la curiosidad de saber de qué manera podian adquirirlo. He anotado. en primer término, una viva inteligencia asimiladora. En seguida. una virtud innata para las lenguas: estos latinos poseen evidentemente una excepcional facilidad; retienen no sólo el sentido de las palabras francesas, más o menos semejantes a su propio vocabulario, sino la cadencia especial de la frase. a que los extranjeros son generalmente rebeldes, y que, sin embargo, es la condición esencial para el aprendizaje de una lengua. Agreguemos el empleo del método direclo: en las clases de los principiantes. el maestro enseña las palabras frente a las cosas mismas. comenzando por los objelos más usuales. Le agrada proceder por interrogaciones: los espiritus vivaces de los alumnos son a menudo solicitados: si, casualmente, el interrogado no responde o responde mal. diez manos se levantan para reivindicar el derecho de hablar en su lugar, diez manos impacientes que se agitan para llamar la atención del profesor. Agreguemos aún que el francés es obligatorio en los exámenes de la enseñanza secundaria, lo que no deja de estimular en cierto 
grado el celo que los candidatos dedican a nuestra lengua. Los que desean ser a su vez profesores. encuentran un obstáculo que en muchos países sería considerado como insalvable: es imposible aprender el francés en Francia. Es largo el camino de Santiago a Paris, y se sabe, por lo demás. que de todos los males que aquejan a los estudiantes. el más grave es la carencia de recursos pecuniarios. Para la inmensa mayoría de ellos, el viaje a Europa sigue siendo un hermoso sueño. Aqui. la buena voluntad de los alumnos y el ejemplo de los profesores dan resultados no solamente admirables. sino casi paradojales. $\mathrm{He}$ oido a un antiguo estudiante del Instifuto Pedagógico de Santiago. que jamás ha puesto los pies en Europa. que no ha frecuentado sino raramente el trato de nuestros compatriotas. improvisar en francés con tanta corrección, justeza y lacilidad. que muchos de nuestros estudiantes parisienses no le habrian aventajado. Tales éxitos suponen. no tan sólo inteligencia, sino la fe que traslada las montañas y que. en la especie. suprime los océanos.

Helos aqui que se adelantan. discurso en mano. estos jóvenes oradores que me han dado tan hermosas pruebas de lo que son capaces. Oigámoslos: los profesores callarán esta vez: es la ocasión de que hablen los alumnos. Estamos en el Colegio Jeanne dArc. es decir. en una escuela tal como sólo las vemos en los sueños: alegre, sonriente. cautivadora, hasta el extremo de que las alumnas están tristes el día de la retirada: dicen a sus padres que ellas preferirian ir a sus clases. y sus padres no dan crédito a sus oídos. La enseñanza se da aqui toda entera en francés, de un extremo al otro de los cursos. Es una de las pequeñas quien ha sido encargada para hablar a nombre de sus compañeras, una hermosa niñita de cabellos ensortijados. coqueta en su uniforme azul marino con cuello blanco. Problema grave iniciarse asi en la elocuencia: no es raro. pues, que ella tiemble un poco. Pero cobra ánimos, hace dignamente su reverencia y dice:

-El Colegio francés Jeanne d'Arc se siente orgulloso y feliz porque tiene hoy el honor de recibiros. 
Hemos preferido hacerlo con toda sencillez. sin decoración. sin piano.

Hemos querido recibiros como se recibe a un amigo. Amigo. si. lo soy vos. que representáis al querido pais de Francia. al que tanto debemos y tanto amamos....

Esta es, por el contrario de las grandes. Estamos ahora en el salón de actos de un liceo de niñas, el liceo Antonia Salas de Errázuriz. Una recepción encantadora, en la que las mismas alumnas han hecho los honores, acaba de terminar: una fiesta literaria y musical va a seguir. Veo. en el programa, que nos aguarda el placer de oir canciones francesas. Cábulas de La Fontaine, sonetos de Henri de Régnier. Entre ese doble regalo. tiene cabida un discurso de saludo, muy bien pronunciado por una de las más distinguidas de las alumnas:

....Es el francés, tan hermoso, tan armonioso y tan rico. lo que, después de nuestra lengua materna. aprendemos con mayor placer: y estamos felices cuando se nos presenta la ocasión de profundizar su estudio. Nuestro interés va creciendo a medida que penetramos en el alma francesa.

Asimismo, nuestra admiración por Francia, por su ciencia. por su arte, por su pensamiento altamente civilizador, va a la par de nuestro reconocimiento por un pais que nos envia des. de tan lejos, emisarios encargados de traernos. con un mensaje de amistad. los reflejos vivientes de su vida intelectual....

La escena cambia ahora: los alumnos del Instituto Pedagógico han tenido la delicada idea de ofrecer. por cuenta suya. un te en honor del profesor extranjero: ante la mesa aun servida. uno de ellos se levanta y habla:

....Y aun. un último mensaje. Cuando lleguéis de regreso a vuestro pais, decid a nuestros camaradas de allá que los chilenos aman profundamente a Francia. de la cual admiran. no solamente los grandes genios cientificos y los grandese scritores. sino también sus hermosas y fuertes instituciones.

Estad cierto de que nuestros volos más sinceros os acompañarán a través de los mares. hasta vuestra querida patria: y si 
algo nos queda aún que pediros. es el que nos dejéis en la esperanza de que algún día repetiréis vuestra visita,

Que esta manifestación no sea una fiesta de despedida. sino la promesa de un próximo regreso. Tales son nuestros deseos. y ésta es también nuestra esperanza.

Estoy invitado a visitar un circulo de estudiantes; el-presidente y los miembros del direetorio me acompañan de sala en sala: charlamos; y. admirado una vez más de la manera como estos jóvenes hablan el francés. no me resisto a felicitarlos. Entonces, dos de entre ellos rien.- - ¿Por qué rien ustedes?Lo más extraño es que hemos aprendido el francés en los $\mathrm{Pa}$ dres alemanes!. Un revuelo se produce en nuestro grupo: se quiere hacer llegar hasta mi a uno de los asistentes que. modesto. se oculta. .Ha escrito una oda a Francia. Es necesario que la recite, de buena o mala gana; $y$ he aqui que se desenvuelven. en efecto, las estrofas armoniosas de un noble poema:

Francia grande. Francia hermosa. dulce tierra solariega. Yo le llevo en lo más hondo de ini fuero espiritual...

Yo palpito en el transcurso de tu historia milenaria.

Yo comprendo lus grandezas, y en la gris. crepuscularia Tarde aciaga de tus penas. siento henchirse el corazón Y nacer. allá en la fibra donde llora la tristeza.

Todo el ritmo de una inmensa, de una ronca Marsellesa. Todo el eco de una cruda, de una negra rebelión...

\section{LA UNIVERSIDAD DE CONCEPCION}

Es la misma invitación cordial. son las mismas atenciones prodigadas desde la hora del arribo hasta la partida; es otra atmósfera: y es, por lo que toca a la enseñanza. el espectáculo de un admirable esfuerzo.

La atmósfera es enteramente provinciana, reposada y deliciosa para los que se sienten cansados del tráfago de las grandes ciudades. Si se quiere evitar el vivir cercados de automóviles. 
hay que venir hasta aqui: ipero es preciso apresurarse! Con esta plaza en que jóvenes y niñas vienen a pasear en derredor. sus calles apacibles. sus casas que se conservan fieles al viejo estilo español, el cerro boscoso en que se apoya el estuario del Bio-Bio, donde viene a perderse. Concepción fiene un carácter de dignidad serena que seduce desde el principio.

Es aquí donde se está creando, con todas sus reparticiones. una Universidad nueva. Es preciso no contar ni con esos Mecenas que en la América del Norte favorecen con sus millones los colegios; ni con el Gobierno. cuyo presupuesto no se equilibra sino a costa de grandes esfuerzos: menos aún con los recursos de los estudiantes, puesto que en Chile toda la Instrucción es gratuita. enseñanza primaria, secundaria. superior: es uno de los principios democráticos a los cuales la nación parece más firmemente fiel. Entonces, ¿cómo hacer? Los hombres ingeniosos y tenaces que quieren que Concepción tenga su Universidad, han hallado, sin embargo, el dinero que les hacia falta. No hablemos de loterias, que están prohibidas en todo el ferritorio de la República. Pero se venderán billetes de suscripción voluntaria: a algunos de estos billetes, sacados a la suerte. corresponderán primas halagadoras: y el dinero ya no faltará... Bienhechora lotería, aun asi disfrazada; y bienhechor dinero. que se convertirá en ciencia. en cultura, en progresol

La valiente conquista se prosigue sin descanso. Esta clinica es enteramente nueva: está provista de los aparatos más perfeccionados. Este laboratorio no existia el año último. El año próximo, si Dios lo quiere. los estudiantes tendrán su ciudad universitaria. De Europa. o más especialmente de Alemania. han llegado tal o cual profesor; este estudiante parte para Europa. Las enseñanzas más directamente ùtiles tienen preferencia sobre las otras: pero éstas tendrán tambiên su turno. De tal manera, el Sur tendrá su institución de alta cultura, no inferior a ninguna otra. y que es digna de inspirar desde luego a sus fundadores el más legítimo orgullo. Si, es admiración lo que merece este noble taller en trabajo, sobre todo cuando se piensa en la suma de voluntad que representa tal esfuerzo. en su elevada 
dignidad y en el lugar que ocupa la Universidad más joven del mundo, vanguardia de la civilización.

\section{EN VALPARAISO}

Apenas he entrevisto la ciudad: activa, totalmente llena de gentes ocupadas que van de las casas de comercio a las casas de banca; opulenta y atravesada de largas avenidas en que circulan pesados camiones cargados de mercaderías. junto a los autos de los dueños: pintoresca en toda la parte alta. con sus casas abigarradas. sus callejuelas dispuestas en escalamiento. sus escaleras. sus pendientes. sus balaustradas. sus terrazas, alegres y paradojales arquitecturas. He ido a la playa elegante que es la prolongación de la ciudad. la perla del Pacífico. Viña del Mar. No he tenido tiempo para detenerme: he sido arrastrado por un movimiento impetuoso y he vivido en un torbellino durante tres dias.

Rápido. Las autoridades nos aguardan para la visita protocolar. La lancha del jefe de la escuadra nos espera para un apresurado paseo por el puerto. El muy amable y muy activo cónsul de Francia, que ha dispuesto los detalles del programa hora a hora, nos espera en su consulado: ya llevamos algún alraso. Los establecimientos franceses nos aguardon: las buenas hermanas de San Vicente de Paul. que sostienen un internado. un externado, un obrador, un dispensario. y que encuentran la manera, no sólo de instruir, sino de alimentar a los pequeños huérfanos. los más desamparados de la ciudad: todo con un minimum de recursos, y con un personal tan reducido, que su tarea resulta aplastadora. Y los padres del Sagrado Corazón. que dirigen un colegio floreciente. Apresurémonos: allí escucharemos a alumnos chilenos que pronucian los más elocuentes discursos franceses: $y$. sobre esto. solicitaremos un dia de asueto para todos los alumnos. lo que nos valdrá el más franco de los éxitos. Y los bomberos franceses. Y los miembros más prominentes de la colonia francesa. que desean recibirnos en sus residencias. Y la colonia francesa, que ha preparado un ban- 
quete suntuoso: Y la conferencia. - ya iba a olvidarla. - que debe verificarse en el salón de actos del liceo de la ciudad. y por la cual tantos chilenos, tantos chilenos amigos de Fran cia se han reunido ya...

¿Cansancio? Seguramente. Pero sobre todo, reconocimiento y alegria. No es necesario recurrir a la figura de retórica para contestar, aunque fuera por diez veces seguidas, a los sentimientos que se desea expresarme: basta hablar de corazón a corazón. No será necesario forzar la memoria para conservar el recuerdo de tantas visiones rápidas, pero intensamente grabadas. Si se me pudiera señalar una como símbolo. se me pondria en gran apuro. por el temor de agraviar a las demás. Si una fuera necesaria, a pesar de todo, yo elegiria ésta.

La colonia francesa nos ha invitado a su circulo. a su hogar: nos detenemos ante el atrayente cuadro que ocupa puesto de honor en una de las salas. Alguien ha tenido la.idea de buscar la fotografía de los franceses de Valparaíso muertos durante la gran guerra: de reconstituirlos en forma conveniente, y. por fin. de agruparlos. Y helos ahi a lodos, cada uno en su individualidad, en su actilud lamiliar, y. sin embargo, unidos. apretados estrechamente. a estos franceses muertos por Francia. Se muestran sin fanfarronería, sencillos, desaliñados y dolorosos. La colonia no se reune sin tenerlos en medio de ella: ellos permanecen aún entre los vivos.

\section{E1. COMITE FRANCE-AMERIQUE}

Dos naciones se aman y se estiman: aun querrian tener la ocasión de decírselo algunas veces. No les basta que sus gobiernos cambien cumplimientos. ni que sus diplomáticos se truequen condecoraciones. Hay Chile y Francia: pero hay también chilenos y franceses. Reunirse, entre franceses y chilenos. cambiar ideas, afirmar sentimientos. disipar los malentendidos. que se prolongan hasta el infinito cuando se callan y que desaparecen avergonzados cuando se provecla luz sobre ellos: anudar relaciones personales, poner nombres sobre los simbolos, ver 
de amar, no entidades. sino seres humanos: he aquí algo que era muy descable. y algo que ahora ha llegado a ser más fácil.

El mérito del éxito es del Comité France-Amérique. Su obra consiste en acoger a los americanos en Francia y a los franceses en América: formar grupos y hermandades. Por mi parte. en todas partes pude probar sus beneficios, en Concepción, en Valparaiso, en Santiago. Gracias a èl. he conocido mejor a los chilenos. y. por lo tanto. los he estimado más. He formado parte de una familia. palabra que jamás deja de ser dulce.

El presidente del Comité France-Amérique de Santiago me ha encargado un mensaje. ¿Quiere usted. me ha dicho. presentar expresamente nuestro recuerdo al fundador de nuestra sociedad? ¿Quiere usled agradecer de parte nuestra al hombre que tuvo la idea de instituir nuestra unión y que la ha mantenido. M. Gabriel Hanolaux? Exprésele que la semilla que él arrojó en nuestro suelo ha germinado bien, y que la cosecha es hermosa.

Está cumplido ya.

\section{LA PARTIDA}

Tocan a su fin los tres meses de mi estada.

A todos los que me han preguntado si sentia añoranzas de mi pais, si no echaba de menos ni Francia ni Paris, he podido responder. hecha la prueba. que nada estuvo más lejos de mi que tal sentimiento. Por el contrario. el tiempo ha corrido tan ligero, el ritmo del último mes se ha acelerado de tal suerte. que me siento admirado al oír cómo suena ya la hora de la partida.

Como hay aqui la costumbre de ir espontáneamente al encuentro de los que llegan y de venir a verlos sin esperar su visita, asimismo hay la costumbre de acompañar hasta la estación a los que se van. Conmovedora coslumbre, a la cual nuestra vida parisiense, desbordada, no nos permite obedecer. cuya dulzura recordaremos siempre. porque el adiós adquiere con 
ella un carácter más sensible, más melancólico y tal vez más memorable. ¡Cuántos amigos reunidos en torno del vagónl ¡Cuánfas manos tendidas! IY qué profundas resonancias despiertan sus palabrasl . Hasta luego. Usted sabe que ya no es un estran. jero. Le contamos entre los nuestros. Le hemos brindado nuestra amistad para siempre... Muchas veces se me hizo oir la Marsellesa en Chile: por una atención suprema, se ha querido que la oiga aún cuando el tren se marcha, de tal manera que mi himno nacional sea el último eco que me lleve. La vista de la estación se apaga lentamente: su huida se acelera; ya no veo sino un grupo compacto en que las figuras se esfuman y del cual surgen movimientos de pañuelos: la masa se reduce, palidece hasta no ser sino un punto que se pierde en el espacio.

\section{LA LI.EGADA AL HAVRE}

Buenos Aires, Montevideo, Rio de Janeiro, Madera, Lisboa: por El Havre es por donde el Hoedic entra en Francia.

Ya no se apresura: su tarea está terminada: bástale esperar la marea para franquear la entrada del puerto, por la noche. Suavemente, perezosamente. se desliza sobre las aguas negras. El mar que del lado de Quessant nos hizo sentir su cólera. se halla ahora tranquilo: ni un soplo de viento. No azota ya los costados de la nave; los acaricia: no tiene. en torno a su lenta marcha, sino un canto lamentable y dulce.

La noche nos envuelve y todo está bañado en sombras. Desde el elevado puente en que nos enconframos, pasajeros fantasmas, vemos surgir confusamente, hacia adelante, una extraña vegetación de mástiles. grúas. escalas, cordajes, telas de araña tejidas en la oscuridad. La voz del comandante sube hasta nosotros: A estribor, un poco.... Más abajo todavia, sobre el puente. más bien se adivina que se oye foda una agitación invisible.

Dero de pronto, alrededor nuestro, delante de nosotros, brillan a lo lejos luces amigables. Alineamientos regulares de luces. apretados como las cuentas de un collar fosforescente, atravie- 
san la inmensidad de la sombra: son las playas normandas. Dos grandes brazos impalpables estienden sobre el mar sus velos mudos y blancos: es el faro de la Hève. Un haz de puntos luminosos escalonados: es Sainte-Adresse. Luces desordenadas, que se aprietan. que centellean. que se mezclan. y que resplandecen, y que parpadean, y que vibran, rojas. verdes. blancas, amarillas; un carnaval de luces; es el Havre. Pequeños barcos pasan junto a nosotros. fuegos fatuos. fuegos danzantes. A medida que nos aproximamos. vemos los grandes reflectores del puerto vaciar de alto a bajo la lluvia de sus luces penetrantes. El agua se anima con reflejos de acero. reflejos de plata, reflejos de oro.

Cuando la nave llega al muelle. la noche ha cerrado ya. No desembarcaremos hasta mañana. Los pasajeros quedarán hasta que llegue el día en el cuerpo del pez monstruoso aprisionado en una poza del puerto, vigilado por los aduaneros.

Mañana veremos a nuestros compañeros, nuestro cielo ligero. nuestras amables colinas, y la gracia de los sauces melancólicos al borde del agua: mañana, con el ruido del tren que se estremece y se agila, entraremos a Darís. la gran ciudad: mañana volveremos al curso normal de nuestra vida, $y$ hallaremos nuevamente. prontos a recobrarnos. nuestras tareas habituales. Y otra. que es nueva. Será menester. por reconocimiento y por justicia, decir lo que me ha sido dado constatar allá lejos: trabajar para que lleguen a ser menos verdaderas estas frases, a menudo y justamente repetidas: -Vosotros nos conocéis mal: vosotros no nos conocéis: jamás habláis de nosotros...,

PAUL. HAZARD

(Traducido para ATENEA de la Revue des Deux Mondes. 15 de Diciembre de 1924). 